\title{
(Des)Reterritorializando o Espaço-Tempo da Loucura: Uma Genealogia Espacial
}

(Un)Reterritorializing the time-space of madness :

A spatial genealogy

Luis Artur Costa,

Danichi H.

Mizoguchi \& Tania M. Galli Fonseca

Universidade

Federal do Rio

Grande do Sul 


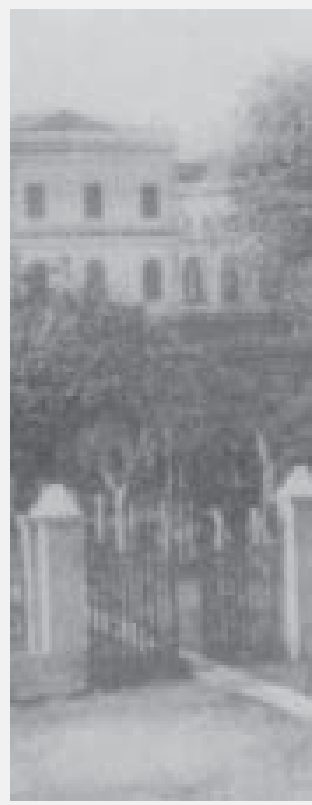

Resumo: Intenta-se, através deste trabalho, dar visibilidade à genealogia do prédio histórico do Hospital Psiquiátrico São Pedro, localizado em Porto Alegre (Brasil). Intriga-nos e nos impulsiona o questionamento referente ao espaço atual da loucura: o que se fez e o que se faz de um dos prédios que, por mais de século, hospedou a loucura porto-alegrense? Qual é o espaço que hospedou e o que passará a hospedar os loucos na cidade?

Palavras-chave: cidade, reforma psiquiatrica, loucura, urbanismo.

Abstract: Through this work we intend to give the Psychiatric Hospital São Pedro (Porto Alegre, Brazil) historical building genealogy some visibility. The questioning related to the present madness space intrigues and encourages us: what has been done and what is being done about one of the buildings that has housed the mad people of Porto Alegre for over a century? What space has housed and what will house the mad people in the city from now on?

Key Words: city, psychiatric reform, madness, urbanization.

\section{Esquadrinhando o espaço urbano: o surgimento do hospício e sua cidade}

No início do século XIX, em Porto Alegre, a assistência médica reduzia-se a iniciativas civis particulares, sem qualquer centralização em um poder imperial, religioso ou científico. Em 1826, a inauguração da Santa Casa de Misericórdia marca o primeiro dispositivo de saúde centralizado, o qual teve, até a metade do século, uma ação exclusivamente assistencial, relegando completamente a questão do tratamento, inclusive pela quase ausência de médicos na província ${ }^{2}$.

A cidade, durante os oitocentos, cada vez mais surgia enquanto malha urbana organizada. Suas ruas abriam-se em retas, alargavam-se passeios e abriam-se passagens, numeravam-se ruas e colocava-se, à porta das casas, uma guarda de alvos trajes e científica conduta ${ }^{3}$. Redigiam normas de conduta pública e privada. Capturavam e ordenavam os fluxos de dejetos. Imprimia-se ordem e vigilância.. A cidade era esquadrinhada em ruas, agora nomeadas e numeradas, estirpada de seus becos, botecos e bordéis, que, com seus freqüentadores, eram alojados em pontos periféricos dos espaços de convivência da cidade (Pesavento, 1991).

A luta se dava não apenas contra a proliferação de doenças pelas más condições de higiene, mas tratava-se também de um saneamento moral contra as casas duvidosas que se multiplicavam em meio às residências familiares, forçando um convívio indesejável para a moral burguesa. Bordéis, becos e botecos serviam de ponto aglutinador aos que não tinham incorporado em si a disciplina mercantil, cristã e ordeira da burguesia: "vagabundos", ladrões e prostitutas, entre outros, maculavam áreas inteiras alojando-se em sua proximidade. Assim, passava pela reorganização urbana o saneamento dessas áreas, dando fim aos becos malditos e lançando seus freqüentadores que 
"Porto Alegre está precisando de um saneamento em regra. Não será este, porém, de ácido fênico ou outros tantos desinfetantes. Fazse tão somente necessária a ação da polícia, sob um ponto de vista importante. É a bem da moralidade, da ordem e da tranqüilidade públicas. Dia a dia vai aumentando, por toda parte desta capital, o número de bordéis, verdadeiros 'germens' do vício e do crime"

Gazeta da Tarde, 30 mar. 1897 não se prestassem, ou não conseguissem, acomodar-se aos códigos de convivência civilizados, aos arraiais em torno da cidade (Pesavento 1991).

"Porto Alegre está precisando de um saneamento em regra. Não será este, porém, de ácido fênico ou outros tantos desinfetantes. Faz-se tão somente necessária a ação da polícia, sob um ponto de vista importante. É a bem da moralidade, da ordem e da tranqüilidade públicas. Dia a dia vai aumentando, por toda parte desta capital, o número de bordéis, verdadeiros 'germens' do vício e do crime" (Gazeta da Tarde, 30 mar. 1897, apud Mauch, 1994, p. 11).

Data de 1857 o primeiro registro de uma ação voltada especificamente para os "alienados mentais": a tentativa de seu degredo para o Hospício Pedro II, no Rio de Janeiro, ação que foi logo abortada e substituída pelo projeto de construção de um hospício para a Província, sugestão apresentada pelo próprio Presidente desta. Pode-se visualizar, a partir dessa substituição, o objetivo da empreitada: trocase o degredo pelo seqüestro.

Não que a Capital estivesse desassistida de um local para seus alienados; afinal, eles eram acomodados em cadeias públicas e, na década de 1860, no "Asylo de Alienados" da Santa Casa. Porém, sua manutenção não era desprovida de problemas, muito pelo contrário ${ }^{4}$.

Os provedores da Santa Casa fazem uma campanha pela construção de um hospício, utilizando-se tanto da argumentação médica da época sobre a necessidade de um lugar específico para o tratamento e assistência de uma doença específica quanto de uma retórica humanitária, apelando para a civilidade cristã de cada um, além de ressaltar sua necessidade para a manutenção da ordem social.

"(...)Entre as obras que todos homens de sentimentos humanitários reclamão como uma das que mais necessita esta província, é um asylo de alienados nas condições exigidas pela sciencia.(...) todos sabem que o essencial de um asylo de alienados é que o edifício seja apropriado a esse fim. (...) E ha de continuar uma sociedade christã e civilizada, a collocar aquelles que perderão a razão, muitas vezes por injustiças da própria sociedade, nas mesmas condições em que coloca o malvado criminoso?!(...) Vagão pela Província muitos loucos e a imprensa de quando em quando registra crimes horriveis por elles praticados; existem em casas particulares muitos outros que as vezes ao menor descuido causão grandes desgraças (...) Enquanto se não construir um Asylo de Alienados nas condições exigidas pela sciencia esses males hão de continuar e augmentar, e a mísera sorte dessas desgraças cada vez se tornará peior' (Relatório do provedor da Santa Casa de Misericórdia," 1874, apud Wadi, 1994, pp. 54-58).

Por mais que esteja sustentado também em um discurso científico como uma das justificativas para a nova construção, este não se apresenta por si, mas enquanto parte do que forma a civilidade moderna, índice do que se busca na realização dessa obra: uma organização disciplinadora do espaço urbano, humanitária e científica. Desde já, não parece que o pio assistencialismo filantrópico dará lugar ao tratamento médico imediato, com a mudança de espaço.

Em 1874, é aprovada a Lei que autoriza a arrecadação de dinheiro para a construção do hospício. O terreno onde se construiria o hospício teria que ser necessariamente fora da cidade, não somente por um isolamento com fins de exclusão, mas também pelo fato de, na época, as teorias médicas prescreverem ao louco o isolamento em contato com a natureza, crendo que esta seria uma força reharmonizadora da percepção desordenada do alienado (Schiavoni, 1997).

Tais cuidados na construção do prédio para um hospício eram comuns nessa época. Na França, a Regulamentação, de 1839, levava em consideração uma quantidade reduzida de 
questões como: salubridade (dentro e fora da edificação); afastamento de qualquer vizinhança para segurança e conforto de ambos os lados; uma separação mínima para dividir o local entre adultos, crianças e entre gêneros e permitir o isolamento dos convalescentes e furiosos, e, por fim, a vigilância sobre os pacientes, que deveria ser garantida pela construção e pelo terreno (Antunes \& Barbosa \& Pereira, 2002). Já o Tratado de Arquitetura, de Louis Cloquet, em 1900, traz estas e outras assertivas com relação às especificidades do espaço manicomial; duas dentre elas são interessantes e devem aqui ser ressaltadas: tem que ser construído em locais que "agradam a vista", e deve antes ter uma geometria retangular dispersiva do que uma radial centralizada, pois esta favorece a classificação dos doentes e não interfere na vigilância, que deveria ser executada no interior das células (Cloquet, apud op.cit., 2002, p.63). Essa, porém, não é a única argumentação que propõe a solução pavilhonar (adotada na construção do Hospício São Pedro). Tenon, em seus estudos sobre a forma arquitetônica perfeita para uma instituição de saúde ideal, decidiu-se pela primazia da solução pavilhonar horizontal (pavilhões ligados por corredores cobertos, ou por galeria central, como no HSP) sobre a radial. Foi motivado não pelas questões referentes à dispersão e à classificação (como Cloquet), mas sim, pensando segundo as categorias funcionais "circulação de ar" e "luminosidade" (Silva, 2001).

Como se pode ver, a construção de um hospício leva em consideração a captura e ordenação de seus fluxos: ar, luz e corpos. Aos fluxos corpóreos, é necessário fixar em espacializações classificatórias, dividindo-os em categorias separadas segundo critérios analíticos vários e impedindo seu encontro, sua mistura, não apenas para evitar a geração de confusão, mas também, se não principalmente, para evitar interações "perneciosas" à saúde dos corpos em geral: contágios, agressões, sujeira, sexo, etc. Já quanto ao ar e à luz, deve-se atentar para a sua maior infiltração possível no espaço hospitalar, impedindo a umidade e a estagnação do ar, produtores de insalubridade. Pela especificidade dos seus enfermos, ao se pensar o espaço manicomial, outros fatores têm que ser levados em consideração, como, por exemplo, a "impressão de liberdade completa" (Olinto, 1930) para tratar dos alienados "sem alterar muito os seus hábitos, sem se sentirem coagidos, sem se aperceberem que estão reclusos" (Olinto, 1930, pp.32-34). Para tanto, devia-se planejar as aberturas, passagens e volumes que permitissem farta incidência solar e renovação do ar constante. Intersecção entre arquitetura e saúde, expressa nas palavras do primeiro diretor do HSP: "O alienista e o arquiteto devem andar de mãos dadas; devem obrar de comum acordo; a construção de um hospício deve ser obra de ambos" (Relatório Hospício São Pedro, 1884, p.04, apud Schiavoni, 1997, p.34).

Inaugura-se o Hospício São Pedro, ainda inacabado, mas já com dois pavilhões dos doze previstos, em 13 de junho de1884 (foram construídos, por fim, somente seis pavilhões ligados por uma galeria central transversal). As notas nos jornais eram de otimismo e felicidade:

"Se nada mais tivermos para mostrar aos estrangeiros que nos visitarem senão o Hospício de Alienados, mereceremos, por certo, os elogios a que temos direito, como um povo civilizado e humanitário" (Souza, 1943, p.76, apud Schiavoni, 1997, p.32).

Como se vê, o hospício serve de monumento à modernidade e humanidade da província, manifestações essas de acordo com os argumentos utilizados pelo Provedor da Santa Casa para convencer a Província da necessidade do HSP. A cidade recebe o HSP não apenas enquanto dispositivo de exclusão que é mas também como o aparelho disciplinador que lhe permite o controle moderno: sem as crueldades da dor pela dor sem função, proporcionar maior ordem à cidade, monumento à civilidade de um povo, à sua capacidade de ser e agir racionalmente, à grande razão branca, neutra,
"Se nada mais tivermos para mostrar aos estrangeiros que nos visitarem senão o Hospício de Alienados, mereceremos, por certo, os elogios a que temos direito, como um povo civilizadoe humanitário"

Souza, 1943, p.76, apud Schiavoni, 1997, p.32. 
reta e regular, a que se credita a capacidade de antever sempre o que deve ser bom, verdadeiro e belo, conceitos unívocos em sua "mono-mentalidade". Assim, a imponência de sua estrutura, que impressiona a quem por ela passa até hoje, não fala apenas de um absolutismo imperial mas também do que é absoluto na modernidade: a razão. Está presente uma harmonia de retas, arcos e simetrias sóbrias que executa uma ação contra a confusão dos sentidos do insano.

Assim surge o Hospício São Pedro, em meio a diversas medidas de disciplinamento da cidade, esquadrinhada, vigiada, dividida-organizada, ela e seus cidadãos, para as relações mercantilsociais se realizarem de modo previsível e controlável, práticas sustentadas por um discurso que prega a modernização e a moralização do espaço urbano a um só tempo segundo uma utopia de civilidade: "a utopia da cidade perfeitamente governada" (Foucault, 1987, p.164).

\section{A luta por esquadrinhar o espaço institucional: a Medicina em busca do seu espaço.}

Se o HSP se inseria na cidade como mais uma ação estratégica na formação de espaços classificatórios e de contenção-ordenação no plano urbano, essa otimização utilitarista ainda não existia no seu próprio espaço institucional. Este servia antes à mera contenção asilar do que à produção de saberes e práticas na busca de controlar e prever o "alienado mental". Instrumento antes apenas administrativo a serviço da Província ao prevenir a desordem do que instrumento médico, tinha o papel de dividir, fixar, anular e marcar uma população em um espaço de exclusão. A luta de então era pela aceitação do hospício e da loucura enquanto domínios de direito da Medicina.

Nessa luta pelo espaço institucional, o próprio hospício constitui-se como uma ação inviabilizadora dos estratagemas alienistas, impedindo uma dispersão classificatória adequada aos padrões de então "[a] única classificação atualmente possível é precisamente incompleta" (Relatório Hospício São Pedro, 1884, p.04, apud Schiavoni 1997, p. 36). Além disso, as práticas que habitavam esse espaço não pertenciam à ordem médica. $\mathrm{O}$ primeiro regulamento do HSP fora escrito pelo presidente da Província, delegando a administração da instituição a um religioso e destituindo, portanto, a autoridade da ciência médica ao transferir para leigos a determinação sobre as internações e a fiscalização sobre o estado mental dos internados a fim de evitar eventuais arbitrariedades (Wadi, 2000). Somava-se a isso a inexistência de um inquérito na admissão que provesse os alienistas das informações consideradas necessárias para a determinação da etiologia da demência (Wadi, 2002).

Temos, então, apenas um prédio de quartos com paredes nuas, desabitadas de práticas médicas, um espaço-cárcere de um hospíciomuro. Impedia-se, assim, uma ação disciplinar não massiva sobre a loucura: ordená-la buscando sua inteligibilidade e utilidade máximas, uma ação de classificação e registro sobre os internos que permitiria o enquadramento destes em diversos locus, cristalizando seu desmedido em um esquema pré-concebido generalizante e atemporal para findar com sua errância, já que, mesmo tendo sua utilidade questionável para um controle da loucura, era, no mínimo, eficiente no controle do louco.

Com o advento da República (1889), algo dessa situação se altera quando as instituições de saúde mantidas pelo Estado passam a ser administradas por este através da figura do médico como legítimo representante de uma ciência, ou seja, de um modo de gerir "neutro", que prescinde de interesses pessoais. Delegando suas instituições às ciências, o próprio Estado Republicano pretendia-se científico, com uma ação "neutra" que visasse sempre ao "bem comum"; buscava diferenciar-se, em muito, do Estado imperial, constantemente atravessado por interesses particulares ${ }^{9}$. 
Porém, tal conquista do espaço manicomial pelos médicos e sua psiquiatria não se dá de imediato, com as letras nos papéis; tal mudança efetuar-se-á com mais de duas décadas de intervalo. Apenas durante as administrações de Jacinto Godoy (1926-1932/1937-1951), a psiquiatria tomará de assalto o HSP: defrontando-se com um "Hospício São Pedro", sua ação visa à transformação do que ele denomina "depósito de alienados em hospital psiquiátrico" (Godoy 1955, p.15). Medicalizar a instituição e a loucura: com isso, não apenas elevava o alienado ao status de doente vulgar (Godoy, 1955) como elevava a psiquiatria ao status de especialidade médica como outra qualquer. Tratava-se de mudar, a um só tempo, a ontologia da loucura com a modificação epistemológica das práticas para, com esta, iniciar, segundo Godoy, a fase positiva da psiquiatria: "já se pode afirmar com desassombro que as moléstias mentais não existem" (Godoy, 1955, p.72). Isso redundará em diversas intervenções sobre o corpo do alienado e do prédio do antigo hospício.

Complexo majestoso, o hospício torna-se hospital e o prédio torna-se cidadela. O ímpeto de gigantismo se expande e o São Pedro se torna uma pequena cidade autônoma com todos os serviços necessários para sua manutenção: todas as especialidades médicas, inclusive maternidade, moradias para funcionários, produção de alimentos, cuidados para com os mortos, etc. Criam-se instrumentos de multiplicação da ação médica dentro (escola de Enfermagem, 1939) e fora (serviço aberto: profilaxia mental, 1938) da Cidade Hospital Psiquiátrico.

Vemos aí um contínuo processo de construção no antes massivo espaço pouco diferenciado do hospício-muro, de uma complexa rede de minuciosas intervenções sobre os internos, intervenções realizadas, em sua maioria, com o fim de "curar" a loucura produzindo, por suaves coações sobre o corpo do louco, a anulação de sua existência enquanto sentir e expressar. Em nada nos admira, então, que a balneotherapia e a clinotherapia tenham adentrado pelo espaço asilar para substituir o uso freqüente de hipnóticos. Manter o louco preso a uma cama ou banheira de água morna, retirando-lhe sensações e expressões, provendo-lhe os limites de uma cama, de uma banheira, evitando-lhe a excitação e o movimento, fazendo com que o seu corpo, embotado ao máximo, se aproprie dos plácidos limites da cama e banheira, exercitá-lo para embotar-se: se de louco a são não passa, ao menos inofensivo e previsível se torna.

Não se trata mais da simples anulação, antes executada pelo hospício-muro (pela disciplinabloco), fixando e marcando, com a morte social, os seus habitantes. Trata-se agora do hospício-máquina, o qual, com sua ação disciplinar capilarizada em pequenas coerçõesexercícios sobre o corpo do louco, age como um aparelho na busca de sua "correção", aplainando seus desvios. É uma intrincada rede de ações agindo sobre o corpo da loucura.

Com essa complexificação executada no HPSP, o espaço geográfico passa a diferenciar-se para dar conta das exigências técnicas das novas funções. Assim, não apenas se multiplicam os espaços existentes no HPSP mas também as especificidades destes para possibilitar o exercício das novas técnicas. Desse modo, as funções passam a fixar-se em espaços determinados, diferenciados em seu preparo especial para estas com seu incremento tecnológico, pois, como se tornam mais complexas as relações que unem espaço e função, multiplicando-se os "pontos de contato" exigidos, torna-se também mais forte e menos flexível essa trama.

A mesma complexificação das práticas e o aumento substancial do número de pacientes exige a constituição de um dispositivo multiplicador da ação médica no interior do hospital: a Escola de Enfermagem instituída por Godoy. Multiplicando olhares, fazeres e saberes, fica garantida a sustentação da rede de intervenções no interior do manicômio.
Medicalizar a instituição e a loucura: com isso, não apenas elevara o alienado ao status de doente vulgar (Godoy, 1955) como elevara a psiquiatria ao status de especialidade médica como outra qualquer. 
O sistema, no entanto, atravessou os muros, esquadrinhando o espaço para além de si (tornando-se ainda maior), garantindo, assim, maior controle sobre a captura dos fluxos para o seu interior. O Serviço Aberto (seguindo modelo da reforma americana, de Beers) é uma ampliação da ação médica sobre o espaçotempo da loucura, saindo dos muros, dando consultas às portas do hospício para os passantes, os fluxos libertos até lá atraídos por questões que lá não os trancafiariam, ou mesmo permitindo que fluxos antes para sempre presos em sua singularidade de buraco negro manicomial possam, por vezes, afastarse deste, já que tem agora a garantia da gravitação em torno do hospício pela manutenção da força de atração-organização médica para além das fronteiras do hospital psiquiátrico, na figura das assistentes sociais, proibidas de entrar nos muros do manicômio e tendo como dever agir da sua porta para fora, adentrando pelas casas das famílias, reproduzindo a voz do psiquiatra em sua prescrição e o seu olhar em sua vigilânciaregistro, expandindo, assim, a ação medicalizante pelo mapa da cidade em casas, salas, vidas, enfim, não contidas no HPSP.

Tal ação representou uma ampliação também temporal da ação, que passa a antever, prevendo e prevenindo a exasperação do bom senso de cada cidadão, adentrando pelo curso do tempo, tomando conta deste em busca de uma etiologia do desmedido que pode afligir o homem moderno. Dessa maneira, mesmo quem não é pode vir a ser, e, por isso, tornase também objeto da psiquiatria, ampliando a espaço-temporalidade no elemento humano: população e ontogenia.

Concentração, complexificação, ampliação (espaço-temporal), instauração de uma economia do espaço e de uma lógica reformadora, adequação da epistemologia psiquiátrica e ontologia da loucura aos princípios da ciência médica de então: aí está a transformação de uma disciplina-muro em aparelho disciplinar; aí está a transformação do hospício em hospital psiquiátrico: “...devem, daqui por diante, riscar de suas fachadas o nome lúgubre de 'hospício', substituindo-o pelo de 'hospital psiquiátrico'..." (Godoy, 1955, p.77).

\section{Espaços}

\section{Fechando coleções}

Assim, concebemos o espaço enquanto dispositivo agenciador de corpos, olhares, fluxos, percebido a partir de algumas práticas da modernidade: a disciplina da modernidade dura. Nesse momento, foram construídos grandes espaços, onde se efetuava um fechamento dos corpos, onde estes recebiam investimentos, pois o valor de produção do corpo para o trabalho não podia mais ser desprezado. Esse afastamento não vem somente proteger os corpos que continuam na cidade, mas retirar o sujeito desviante do contexto complexo da cidade para outro: linear, planificado, previsível e controlável, corpos investidos para aumentar, a um só tempo, suas habilidades e docilidade. O "espaço fechado" dessas instituições não é literalmente fechado. Por mais que o muro e a grade, instrumentos de contenção-prisão e não de proteçãofortaleza, sejam ícones e práticas espaciais comuns de tais instituições, o "espaço fechado" remete a uma auto-referência instituída antes pelo esquadrinhamento do espaço do que por seu cercamento. É a estrutura classificatória, que posiciona e articula os corpos e seus comportamentos, que os captura em um sistema de ritmos espaço-temporais - hábitos que imprime o dito "fechamento" ao sujeito, encerrando-o, com essa captura, em linhas e colunas: a solidez fixa o espaço e prende o tempo; espaços fixos e tempos presos subjetivam, fazem ecoar saberes e poderes específicos.

Encerrados não somente por contenção, mas também, antes, por inclusão, nessa estrutura: colocando-se em co-tensão com seu sistema de forças, é o fechamento dos 'quadros' feitos no séc. XVIII de que nos fala Foucault (1987, 
p.127), quadros que efetuavam "classificações racionais" com fins de repartir, regularizar, observar, registrar, controlar, etc., enfim: fechar em um quadro esquadrinhador. Visavam a dividir o espaço e o tempo (duração) em segmentos sucessivos e paralelos (op.cit., p.134) e organizá-los em seqüências e seqüências de seqüências segundo um quadro analítico. Estratégia de poder, histórica e específica de determinada época, diz respeito a instituições como a escola, a prisão, o exército e o hospital (Machado, 1979).

\section{Abrindo autopistas}

Os fluidos "não podem suportar uma força tangencial ou deformante quando imóveis", pois "sofrem uma constante mudança de forma quando submetidos a tal tensão" (Bauman, 2001, pág. 7): escorrem, inundam, vazam. Os sólidos, ao contrário, não fluem: resistem a deformações, existem para conter e ser contidos, disciplinam. Do encontro com os fluidos, os sólidos não emergem intactos. Encharcam-se, amolecem, sofrem infiltrações, esboroam e são levados pelo vento a novas paragens, espalhando-se sobre tudo, como aquele pó quase imperceptível que se acumula sobre as coisas sem sabermos ao certo de onde vem: provavelmente de tudo. De tudo sobre tudo ao sabor do vento, o que era sólido continua lá, de outro modo, mais sutil, mas não menos concreto. A fluidez impossibilita as cercas e subverte a estruturação temporal moderna. Em uma configuração espaçotemporal fluida (Bauman, 2001), as respostas espaço-temporais à historicamente mutante questão da loucura são também fluidas. Aquilo que sempre fora duro e sólido, o imenso e majestoso hospital psiquiátrico disciplinar, respingará na forma de múltiplas gotículas. Intitulada anti-manicomial, a reforma psiquiátrica postula a substituição da solidez espaço-temporal no trato para com a loucura: "As sociedades disciplinares são aquilo que estamos deixando para trás, o que já não somos. Estamos entrando nas sociedades de controle, que funcionam não mais por confinamento, mas por controle contínuo e comunicação instantânea" (Deleuze, 1992, pp. 215-216).

Assim como o manicômio surgiu em malha urbana que se disciplinava em linhas-colunas seqüenciais que, em seu atravessamento, formavam locus classificatórios, alguns dos quais anuladores ou reformadores, como no caso do hospício, a cidade, onde esse hospital psiquiátrico se fragmenta e intensifica sua permeabilidade às ruas, é uma cidade fragmentada em unidades privativas (domicílios) e semi-privativas (shoppings, hipermercados, centros de lazer, etc.) de convivência, onde cada vez mais o dito espaço publico é esvaziado de sua função enquanto lugar de encontros citadinos, tornando-se estritamente espaço de percursos entre pontos privativos: um deserto social habitado por uma multipolaridade de oásis controlados (pela segurança privada, câmeras, condicionadores de ar, iluminação artificial, som ambiente, etc.).

A cidade onde surgira o Hospício São Pedro era ainda uma cidade em formação de sua identidade unívoca, claramente afirmada em uma oposição cidade-campo, sustentada pelo meio de transporte então em voga: o trem. Posteriormente, a cidade se entrega a outros transportes (carro, ônibus e metrô), afirmando uma primeira cisão em sua imagem, mas mantendo ainda uma divisão concêntrica: centro e periferia. Já a cidade contemporânea vê proliferar, em sua malha, uma diversidade de centros-periferias espalhados por diversas regiões (Virílio, 1993). Do mesmo modo, o urbanismo passou de uma época onde imperava o planejamento dos espaços urbanos para uma época em que, esgarçada pela exigência de mobilidade do mercado, a cidade acelera seu metabolismo, pululam nascimentos e mortes pelo seu corpo; um processo constante e cada vez mais rápido de demolição-construção passa a atuar como uma das principais estratégias de sua remodelação. Há, cada vez menos, um plano geral. O planejamento da cidade é um assunto cada vez menos falado (Arantes, 1998); responde-se somente a demandas imediatas. 
É a mudança da cidade planejada para a cidade negociada, o papel do urbanista "já não seria dispor ordenadamente sobre o território objetos mais ou menos permanentes, senão colocar em cena a incerteza e o caos do momento" (Rem Kolhaas, apud Limena, 2001, pág. 54). Desse modo, por exemplo, as práticas de segmentação antes exercidas pelos higienistas através do Estado e as grandes intervenções sobre a cidade (como o hospício) hoje se executam com a capitalização (e a decorrente valorização e reforço na vigilância) de certas áreas, que se tornam de difícil acesso à população considerada indesejada (loucos, moradores de rua, prostitutas, etc.). Segundo essa lógica, funcionam, por vezes, certos projetos de revitalização urbana que simplesmente expulsam a população marginal que ali habitava, desconsiderando sua existência.

Fora dessas áreas de ambientes controlados, as ruas abrem-se em um fluxo desvairado obrigatório: siga livre! Sem atrito, sem encontro ou desvio, corpos fluem, rápidos corpos anônimos pelas ruas. Espaços de ninguém, apenas de passagem, ali passam ao lado das grades do antigo hospício, que enferrujam sem serventia, pois todos já se cercaram do imprevisto em seu domicílio, cela privativa, gorda de espaços virtuais. O desvio de olhar, o passar reto, a reclusão em "prisão" domiciliar torna possível, assim, a coexistência no meio urbano.

Dessa forma, instaura-se o regime do espaço contemporâneo: a aceleração-fluidificação das vias e a intensificação-privatização dos pontos ligados por tais vias, que se intensificam não mais pela lógica da concentração como no urbanismo moderno, pela simples aproximação, aglomeração e ampliação dos conjuntos de pontos; há um processo de contração, com a multiplicação de pontos densos pela sobreposição de camadas intensivas de espaços virtuais. Temos o mundo na sala e a sala no mundo, uma "onipresença planetária" (Chesneaux, 1995), uma "contração telúrica" (Virilio, 1994).
Em uma cidade multipolar justaposta, que lida com as contingencialidades do instante negociado em uma rede urbana fragmentada, as estratégias para com a população considerada desviante também vão sofrer suas modificações. As práticas de normalização tornam-se, então, mais sutis e flexíveis, adaptando-se e criando os "novos tempos". Assim, cada vez mais fala-se em penas alternativas, pulseiras com GPS e afins quanto às práticas penais; divide-se o que antes era a Fundação de Bem-estar do Menor em duas e tenta-se gerar, para uma delas, um sistema em rede que simule um lar em contraponto às antigas edificações totais.

Do mesmo modo, as práticas para com a loucura buscam dispersar-se na malha urbana para lidar com o agudo e o fugaz através de pequenas intervenções localizadas espaçotemporalmente e precisas em sua efetividade. Dão conta, assim, de modular a estilística existencial do seu paciente em sua relação com a cidade, propiciando somente a sustentação mínima necessária para a continuidade dessa relação, sem a antiga dispersão de energia exigida para o moldar da cronificação que, por se pretender definitiva, findava, muitas vezes, por nunca ocorrer em seu planejamento prescritivo de micro exercícios-coações. Instauram-se novas práticas que, por sua sutileza e flexibilidade, conseguem lidar com os fluxos em movimento sem a necessidade de estancálos em grandes espaços de fechamento. $\mathrm{O}$ próprio fechamento muda de sentido, sendo agora sinônimo de privacidade e não de privação. É estar de posse da chave e poder ver-se livre dos fluxos misturados, caóticos, não homogeneizados que perambulam pelas ruas. A lógica do fechamento se torce: do fechar ao diferente, passamos a segmentar o homogêneo.

A convivência na cidade já não se dá como antes em decorrência da fragmentação pela velocidade dos fluxos e intensificação dos pontos. Os lugares de convivência que restaram são, em sua maioria, fechados, e, de lá, o louco, se incômodo, é retirado. Desse modo, ainda 
que permaneça uma luta essencial, a inclusão da loucura, nesse espaço, pelo esvaziamento dos grandes manicômios e hospitais psiquiátricos, fala muito das políticas contemporâneas de controle. O espaço privativo capitalizado pelo próprio louco, individualizante e inserido no contexto urbano, não garante, por si, o fim do isolamento, da clausura. Para além do mero deslocamento de corpos, devemos instituir, ao mesmo tempo, um deslocamento em nossas práticas, que não podem ser ingênuas para com os enunciados do urbano e, por isso, devem estar voltadas para sua subversão. Do mesmo modo que o espaço asilar foi tomado um dia pelas práticas médicas, devemos agora intensificar uma tomada de nossas práticas pela cidade, pensando os hábitos, habitares, cotidianos, itinerários, vizinhanças, etc. na busca de não cedermos à sutileza das novas prisões e seus cárceres solitários.

Luis Artur Costa - graduando do Curso de Psicologia da UFRGS (Bolsista PIBIC-UFRGS)

Danichi H. Mizoguchi - graduando do Curso de Psicologia UFRGS

Tania M. Galli Fonseca - Profạ do Curso de Pós-graduação em Psicologia Social e Institucional do Instituto de Psicologia da UFRGS.

Rua Campos Salles, 262/ Bairro Auxiliadora/ Porto Alegre/RS - 90480-030 tel.: (51) 33285350 Emails:tfonseca@via-rs.net - lartur@cpovo.net

ARANTES, Otília B. Fiori. Urbanismo em Fim de Linha e outros Estudos sobre o Colapso da Modernização Arquitetônica. São Paulo: Editora da Universidade de São Paulo, 1998.

ANTUNES, Eleonora Haddad; BARBOSA, Lúcia Helena Siqueira; PEREIRA, Lygia Maria de França. Psiquiatria, Loucura e Arte: Fragmentos da História Brasileira. São Paulo: EDUSP, 2002.

BAUMAN, Zygmunt. Modernidade Líquida. Rio de Janeiro: Jorge Zahar Ed., 2001.

CHESNEAUX, Jean. Modernidade Mundo. Rio de Janeiro: Vozes, 1995.

DELEUZE, Gilles. Conversações, 1972-1970. Rio de Janeiro: Ed. 34, 1992.

FOUCAULT, Michel, Michel. Vigiar e Punir: Nascimento da Prisão. Petrópolis: Vozes, 1987.

GODOY, Jacintho. Psiquiatria no Rio Grande do Sul. Porto Alegre: sem editora, 1955.

LIMENA, Maria Margarida Cavalcanti. Cidades Complexas no Século XXI: Ciência, Técnica e Arte. São Paulo: São Paulo Perspec., vol. 15, no 3, jul./set 2001, pp, 37-44.

MACHADO, Roberto. Por uma Genealogia do Poder. In Foucault, Michel. Microfísica do Poder. Rio de Janeiro: Edições Graal, 1979, pp. VII-XXIII.

MAUCH, Claudia. Saneamento Moral em Porto Alegre na Década de 1890. In Porto Alegre na Virada do seculo 19: Cultura e Sociedade. Porto Alegre: Editora da UFRGS, 1994, pp. 09-24.
PESAVENTO, Sandra Jatahy (coord). Memória Porto Alegre: Espaços e Vivências. Porto Alegre: Ed. Da Universidade/UFRGS; Prefeitura Municipal de Porto Alegre, 1991.

SCHIAVONI, Alexandre Giovani da Costa. A Institucionalização da Loucura no Rio Grande do Sul : o Hospício São Pedro e a Faculdade de Medicina. Dissertação de Mestrado em História. Universidade Federal do Rio Grande do Sul, Porto Alegre, 1997.

SILVA, Kleber Pinto. A Idéia de Função para a Arquitetura: o Hospital do Século XVIII. In: www.vitruvius.com.br/arquitextos/ arq.000/especial.asp, fev/dez 2001.

VIRILIO, Paul - O Último Veículo. Revista 34 Letras, no 5/6. Rio de Janeiro: 1994, pp. 38-48.

O Espaço Crítico. Rio de Janeiro: Editora 34, 1993. WADI, Yonissa Marmitt. Um "Palácio para Guardar Doidos": a Construção do Hospício São Pedro e o Surgimento da Psiquiatria no Rio Grande do Sul. In Porto Alegre na Virada do Século 19: Cultura e Sociedade. Porto Alegre: Editora da UFRGS, 1994, pp. 43-62.

Aos loucos, os Médicos: a Luta pela Medicalização do Hospício e Construção da Psiquiatria no Rio Grande do Sul. Hist. Cienc. Saude, vol.6, no.3.Manguinhos: 2000, pp.659679.

Palácio para Guardar Doidos: uma História das Lutas pela Construção do Hospital de Alienados e da Psiquiatria no Rio Grande do Sul. Porto Alegre: Editora da UFRGS, 2002. 